\title{
Fluid Dynamic Comparison of AdBlue Injectors for SCR Applications
}

\author{
Yujun Liao, Panayotis Dimopoulos Eggenschwiler, and Alexander Spiteri \\ EMPA
}

\author{
Lorenzo Nocivelli and Gianluca Montenegro \\ Politecnico di Milano
}

Konstantinos Boulouchos

Swiss Federal Institute of Technology

\begin{abstract}
The injection process of urea-water solution (AdBlue) determines initial conditions for reactions and catalysis and is fundamentally responsible for optimal operation of selective catalytic reduction (SCR) systems. The spray characteristics of four, commercially available, injectors (one air-assisted and three pressure-driven with different nozzle-hole configurations) are investigated with nonintrusive measuring techniques.

Injection occurred in the crossflow of a channel blowing preheated air in an exhaust duct similar configuration. The effect of several gas temperatures and flows on the spray propagation and entrainment has been extensively studied by shadow imaging. Shadow images, in addition, show that the spray of the pressure-driven injectors is only marginally affected by the gas crossflow. In contrast, the air assisted spray is strongly deflected by the gas, the effect increasing with increasing gas flow. Phase Doppler Anemometry (PDA) measurements delivered droplet size distributions and droplet velocities. Measurements have been performed in several locations near the opposed channel wall area. Sauter mean diameters of the droplets from the pressure-driven injectors are between $60-80 \mu \mathrm{m}$ while of the air assisted $20 \mu \mathrm{m}$. Higher velocities have been associated with the larger droplets in the pressure-driven spray after the primary breakup while droplet velocities have been evenly distributed to all droplets sizes in the air-assisted spray.
\end{abstract}

CITATION: Liao, Y., Dimopoulos Eggenschwiler, P., Spiteri, A., Nocivelli, L. et al., "Fluid Dynamic Comparison of AdBlue Injectors for SCR Applications," SAE Int. J. Engines 8(5):2015, doi:10.4271/2015-24-2502.

\section{INTRODUCTION}

Successful NOx emission abatement from Diesel engines requires further optimization and enhancement of existing urea-SCR systems $[\underline{1}, \underline{2}]$. The main challenges are maximizing NOx reduction performance and minimizing ammonia slip as well as formation of deposits $[\underline{3}, \underline{4}]$. Shortcomings are mainly due to incomplete urea decomposition $[\underline{5}, \underline{6}]$ and substantial non-uniformity of the spatial distribution at the catalyst entrance [7], both attributed to the dosing system. So far, studies have focused on the main reactions and selective catalysis of NOx with ammonia $[\underline{2}, \underline{8}, \underline{9}, \underline{10}, \underline{11}]$. Investigations of the urea decomposition process to ammonia $[\underline{5}, \underline{6}$, $\underline{12}, \underline{13}, \underline{14}$ ] have proven invaluable for efficient system design, as urea decomposition greatly determines required mixing lengths and deposit formation. Experimental studies on the injection for SCR purposes are however scarce. The lack of knowledge in this field restricts options to optimize current systems, since initial conditions of the spray and its evaporation are unknown.
Improved mixing not only facilitates NOx conversion, lowers both NH3 slip and deposit formation, but inherently leads to smaller sizing of the aftertreatment systems - an intrinsic demand of automotive applications. Attempts have been made to address this issue with the installation of different mixing devices and flow homogenizers including structured metallic substrates [15], wire-meshes [1ㅡ], or two step mixers [17]. The comparative effectiveness of different devices has been investigated both experimentally and numerically [18]. To this end, the effect of injection type, location, and pressure on the urea evaporation rate and uniformity of the ammonia distribution within an exhaust duct have been investigated to determine aspects of optimum system design [19, 20, 21]].

Attempts at modeling, simulation and optimization of SCR systems have been conducted $[\underline{19}, \underline{20}, \underline{21}, \underline{22}, \underline{23}, \underline{24}, \underline{25}, \underline{26}, \underline{27}]$. Numerical simulations of different urea injection configurations have been performed [19]. High speed photography and particle sizing have been employed to determine urea spray pattern parameters, which 
were used as input for a CFD model [27]. A model for urea-injection while taking into account interaction with exhaust tubing has also been developed $[\underline{22}, \underline{23}]$. Coupling of spray dynamics and turbulence with chemical reactions in vehicle exhaust gases has been reported too $[\underline{24}, \underline{25}, \underline{26}]$. In the above cases, experimental data on aspects of SCR systems was either explicitly not available[199], limited to a few sources or had to be generated specifically for the study in question $[\underline{22}, \underline{23}, \underline{27}]$.

Fluid dynamic investigation of urea-water SCR sprays have been conducted in our laboratory in the last years based on a specifically designed test rig having exhaust similar conditions while providing the possibility to set exact mass, temperature and composition of the gas flow. The fluid dynamic behavior of a 6-hole SCR injector spray was extensively investigated [28], characterizing the macro spray properties. The spray morphology and droplet size distributions under exhaust flow conditions have been used to validate numerical simulations $[\underline{29}, \underline{30}]$. The influence of two different injectors on the NOx conversion of an SCR catalyst was investigated in [31]. The temperature evolution on the exhaust gas duct being hit by the urea water spray has being also investigated [32].

The present work compares four commercially available injectors experimentally in terms of the bulk spray analysis, droplet size and droplet velocity distributions and predicts the suitability for mobile SCR applications. In addition, the results provide valuable initial boundary conditions for numerical modelling of the SCR system or alternatively enable the validation of SCR spray models.

\section{EXPERIMENTAL SETUP}

The experiments were conducted in the flow laboratory at EMPA, Dübendorf. This laboratory was designed for the experimental investigation of urea-water injection into the exhaust channel for SCR application. For the scope of this paper, all experiments were done with dry air as exhaust flow to investigate the fluid dynamic behavior of the injection spray. The air is taken from EMPA pressurized air network and fed into a large dampening volume to get rid of possible oscillations. The air flow is then led through three heating units to reach the target temperature. The prepared gas flow subsequently passes through the injection channel assembly which allows optical access from four directions, two from the sides, one from the top and one from the bottom. Figure 1 shows an overview of the exhaust flow channel. In this work, the chamber with a square cross section of $80 \mathrm{~mm}$ by $80 \mathrm{~mm}$ and $150 \mathrm{~mm}$ in length is used. The gas flow through the measurement chamber can be regulated up to $450 \mathrm{~kg} / \mathrm{h}$ and $500^{\circ} \mathrm{C}$, which allows the reproduction of engine exhaust like conditions.

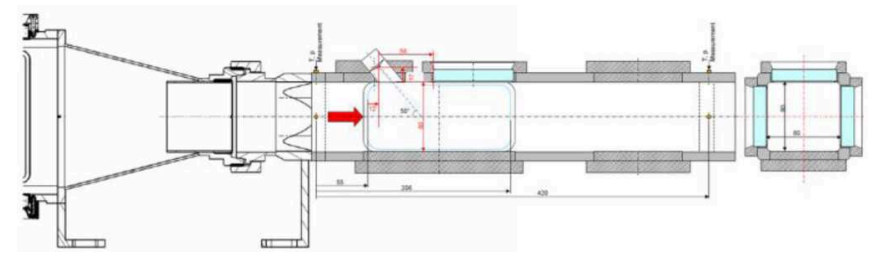

Figure 1. Schematic diagram of the EMPA high temperature flow channel.
Table 1. Characteristics of the four SCR injectors

\begin{tabular}{|c|c|c|c|c|}
\hline Injector & A-A & P1-6H & P-3H & P2-6H \\
\hline Driven mechanism & air-assist & pressure & pressure & pressure \\
\hline Pressure & - & $9 \mathrm{bar}$ & $9 \mathrm{bar}$ & $9 \mathrm{bar}$ \\
\hline Air-pressure & $1.5 \mathrm{bar}$ & - & - & - \\
\hline Static flow rate & $2.64 \mathrm{~kg} / \mathrm{h}$ & $15.2 \mathrm{~kg} / \mathrm{h}$ & $7.2 \mathrm{~kg} / \mathrm{h}$ & $7.3 \mathrm{~kg} / \mathrm{h}$ \\
\hline Nozzle diameter & $970 \mu \mathrm{m}$ & $210 \mu \mathrm{m}$ & $190 \mu \mathrm{m}$ & $130 \mu \mathrm{m}$ \\
\hline Nozzle number & 1 & 6 & 3 & 6 \\
\hline Spacing diameter & - & $1.3 \mathrm{~mm}$ & $1.9 \mathrm{~mm}$ & $1.9 \mathrm{~mm}$ \\
\hline
\end{tabular}

Table 1 shows the injector characteristics including: driven mechanism, working pressure, static flow rate and nozzle geometries. The injector was mounted on the top of the measurement chamber, $50^{\circ}$ inclined to the gas flow direction. The high pressure system of the urea dosing unit can deliver fluid pressure of up to $15 \mathrm{bar}$. The pressure-driven injectors were operated with a back pressure of $9 \mathrm{bar}$ during experiments and the air-assisted injector worked with an air pressure of 1.5bar. Figure 2 shows the stereomicroscopic photographs of the nozzle tip configuration of the four commercial SCR injectors investigated. A-A is a single-hole air-assisted injector. The intermediate ring between the injection nozzle and the air nozzle is $310 \mu \mathrm{m}$ thick and the width of the air nozzle is $165 \mu \mathrm{m}$.
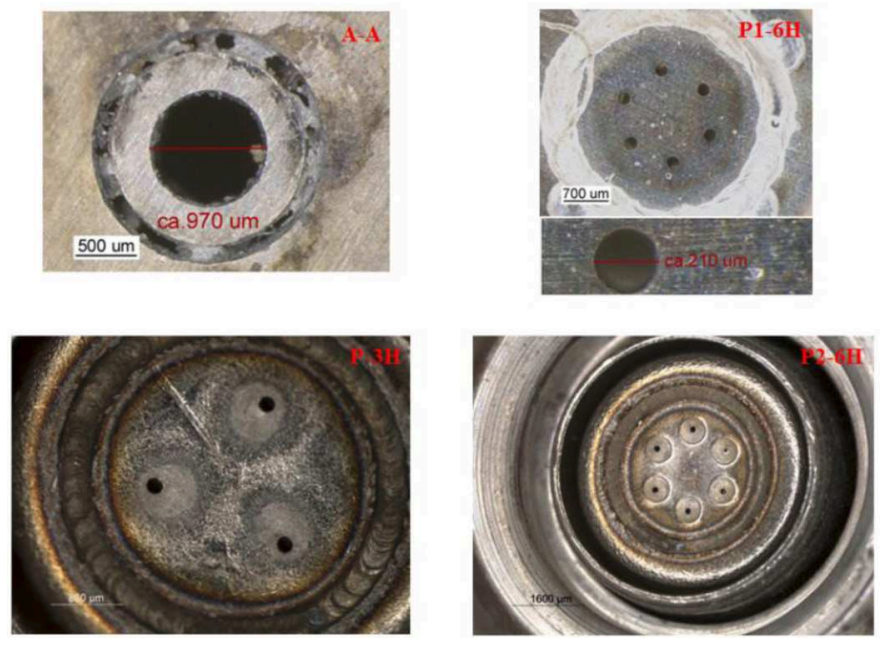

Figure 2. Stereomicroscopic photographs of the nozzle tip configuration of the four commercial SCR injectors investigated.

In this study, shadow imaging and phase Doppler anemometry (PDA) have been applied to investigate the behavior of the spray. For shadow imaging, the optical system was set up according to Figure 3 . The laser which sat at the back of the injection chamber was expanded over a hemispherical lens to illuminate the diffusion plate, in which way a uniform bright background was created. And the camera was located on the other side of the injection chamber to take pictures of the spray in front of the illuminated background. On the images captured by the camera there are shadows, where the laser light has been scattered away by the spray droplets, being visible over a bright background as shown in Figure 3 . The background illumination was done by using Cavitar CAVILUX smart which is a 
pulsed diode laser light source with a wavelength of $690 \mathrm{~nm}$. Laser pulses of $40 \mathrm{~ns}$ and $1 \mathrm{~Hz}$ synchronized with the injection event were used to avoid significant movement during the laser pulse and overexposure of the camera sensor. The PCO Sensicam camera with a resolution of 1040 by 1376 was used as the recording source.

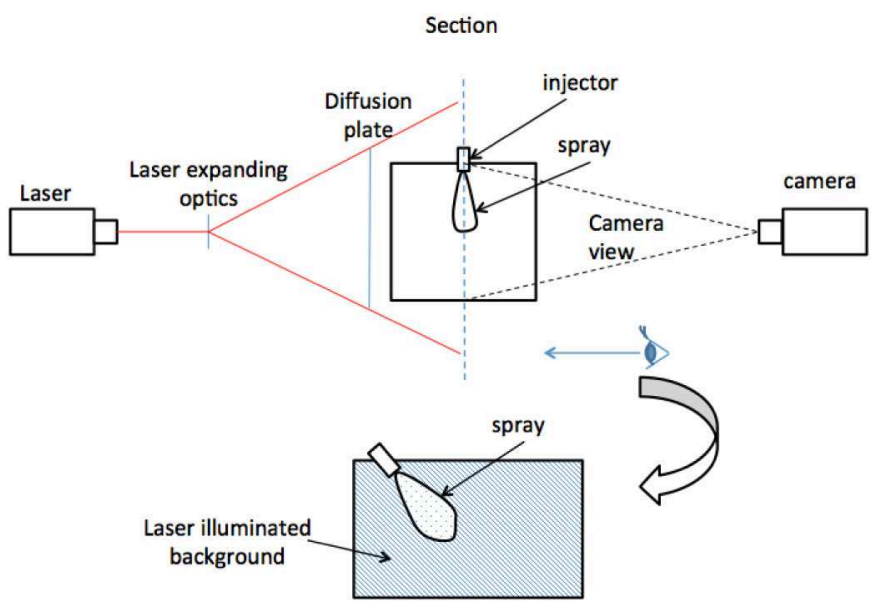

Figure 3. Schematic diagram of shadow imaging setup

PDA optical setup has been described in detail by a previous work [30] which was done on the same test bench.

Figure 4 displays the experimental region of interest of shadow imaging and PDA. The orange box is the shadow imaging region of interest and the green line indicates the plane for PDA measurement.

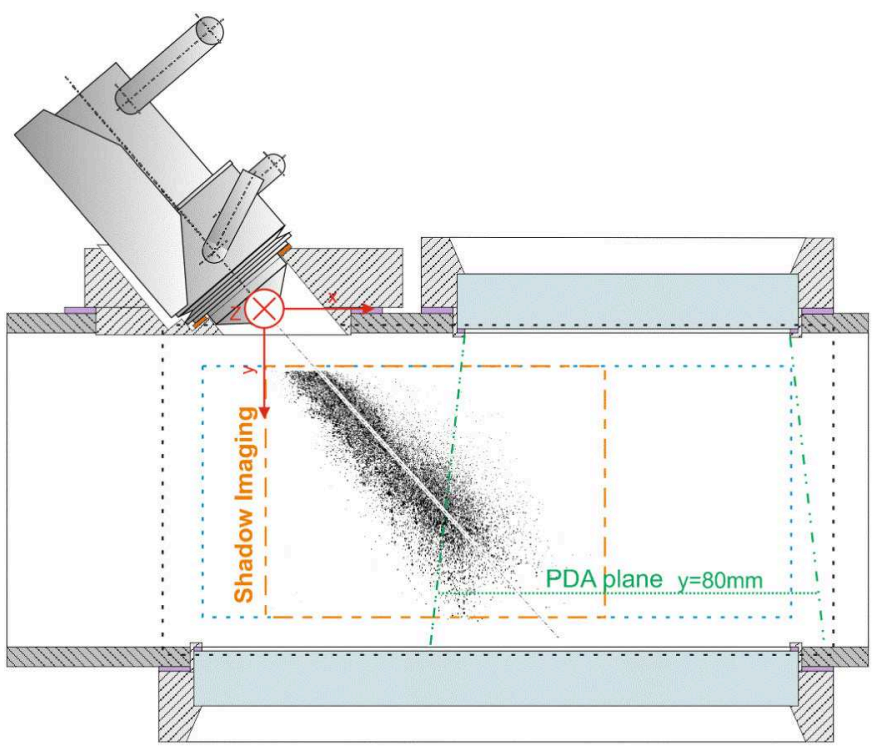

Figure 4. Experimental region of interest of the optical experiments: shadow imaging and PDA.
Previous study [ $\underline{28}$ ] proves that the injected fluid water and Adblue show similar behaviors in terms of the bulk spray properties and the droplet size distributions. Thus, water sprays were used in this work.

For both shadow imaging and PDA measurements, relevant flow conditions were chosen. They are similar to exhaust gas conditions at catalyst inlet. Table 2 shows the channel flow conditions at which different optical techniques were applied.

Table 2. Experimental flow conditions

\begin{tabular}{|c|c|c|c|}
\hline Temperature $\left[{ }^{\circ} \mathrm{C}\right]$ & $\begin{array}{c}\text { Flow rate } \\
{[\mathrm{kg} / \mathrm{h}]}\end{array}$ & $\begin{array}{c}\text { Mean gas velocity } \\
{[\mathrm{m} / \mathrm{s}]}\end{array}$ & $\operatorname{Re}[-]$ \\
\hline 200 & 100 & 5.8 & 13441 \\
\hline 200 & 200 & 11.6 & 26881 \\
\hline 200 & 300 & 17.5 & 40322 \\
\hline 300 & 100 & 7.0 & 11780 \\
\hline 300 & 200 & 14.1 & 23560 \\
\hline 300 & 300 & 21.1 & 35340 \\
\hline
\end{tabular}

\section{RESULTS AND DISCUSSIONS}

This section is organized in the following way. Firstly, shadow imaging shows the overall shape of sprays from different SCR injectors and also the influence of the exhaust flow conditions on the overall spray outline. Comparative analysis of droplet size distributions from PDA measurements on the near-wall plane provides a good indication of the atomization efficiency of the different injectors studied and gives the initial conditions of the spray-wall interaction together with the droplet velocities. Finally the study is completed by the determination of droplet volume flow rates at different locations for different droplet sizes.

\section{Spray Contours Analysis}

Shadow imaging is employed to visualize the overall shape of the sprays from the four injectors. Figure 5 shows the spray contours at the same exhaust flow temperature of $300^{\circ} \mathrm{C}$ but at different exhaust mass flow rates $100 \mathrm{~kg} / \mathrm{h}, 200 \mathrm{~kg} / \mathrm{h}$ and $300 \mathrm{~kg} / \mathrm{h}$. The images are obtained through binarizing the averaged image of 120 raw images which were taken at $16 \mathrm{~ms}$ after the electronic start of injection.

Fundamentally different to the other three injectors, the air-assisted injector spray features increasing deflection of propagation with increasing exhaust mass flow rate. With increasing exhaust flow velocity the spray tends to propagate along the axial flow direction. As the spray moves coaxially with the exhaust flow, the droplets mix better with the exhaust flow and wall impingement is minimized. This behavior is favorable for the SCR application. 
The spray from the 3-Hole pressure-driven injector has three distinct spray cones, whereas sprays from the other two pressure-driven injectors merge into a single spray cone. This is due to the relatively large circumferential separation of the nozzle holes $\left(120^{\circ}\right)$ and the larger ratio of the nozzle diameter to the spacing radius, as seen in Table 1 and Figure 2. This phenomenon prevents the formation of a large unified liquid pool on the opposed channel wall. Nevertheless, the liquid pool forming on the opposed wall is substantial [32]. This can be detrimental for the SCR systems operation. In [르 we have shown that the local cooling effect is strong, while under certain flow conditions the local wall temperature fells below $100^{\circ} \mathrm{C}$ leading to permanent liquid film formation.

Comparing the different color contours in Figure 5, the spray contour shrinks with the increasing exhaust gas flow velocity. The shrinking evidences increasing small droplet entrainment with increasing gas flow. As can be expected, the spray wall impingement also decreases with the increasing gas flow velocity. The images of the sprays of the two 6-Hole injectors show also that the exhaust gas flow affects only the downwind contour of the spray and does not affect the upwind contour.

Based on extensive investigations $[\underline{28}, \underline{32}]$ we can conclude that the sprays from pressure-driven injectors are hitting the opposed wall always at the same location, regardless of the flow properties.
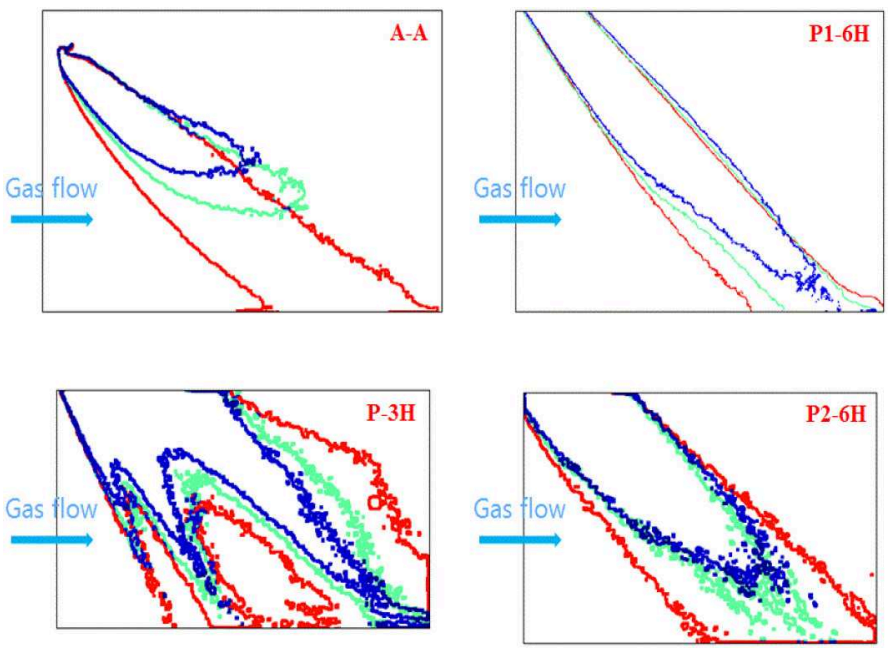

Figure 5. Shadow imaging contours at different flow conditions for the four commercial SCR injectors (gas flow conditions: $300^{\circ} \mathrm{C}$, red: $100 \mathrm{~kg} / \mathrm{h}$, green: $200 \mathrm{~kg} / \mathrm{h}$, blue: $300 \mathrm{~kg} / \mathrm{h}$ )

\section{Droplet Sizes and Velocities}

PDA measurements were conducted on the plane $y=60 \mathrm{~mm}$ for the injectors A-A and P1-6H, $\mathrm{y}=80 \mathrm{~mm}$ for the injectors $\mathrm{P}-3 \mathrm{H}$ and $\mathrm{P} 2-6 \mathrm{H}$ at different transverse locations. In this section, the droplet size distributions, droplet velocities and droplet volume flow rates will be shown and discussed.

\section{Droplet Size Distributions}

The figures shown in this section contain the droplet size distributions and droplet volume distributions. The size and volume distributions are significant for the mass and heat transfer issues of the spray in the exhaust gas flow. The droplet volume distributions determine the droplet mass distributions and have great influence on the effectiveness of the selective catalytic reduction reactions in a catalyst downstream. Figures $6, \underline{7}, \underline{8}, \underline{9}$ show such distributions for the four different injectors at exhaust gas flow condition of $300^{\circ} \mathrm{C}$, $100 \mathrm{~kg} / \mathrm{h}$.

Droplet sizes of air-assisted injection are considerably lower than those of the other three injectors. From the droplet size distribution on the left, it's seen that $80 \%$ percent of droplets are smaller than $18 \mu \mathrm{m}$ and there is no droplet which is larger than $100 \mu \mathrm{m}$. However, the last one percent of droplets which are bigger than $39 \mu \mathrm{m}$ contribute to $22 \%$ percent of the total mass. Nevertheless, the air-assisted injector has been seen as a better atomization source for this purpose, compared to the conventional pressure-driven injectors.
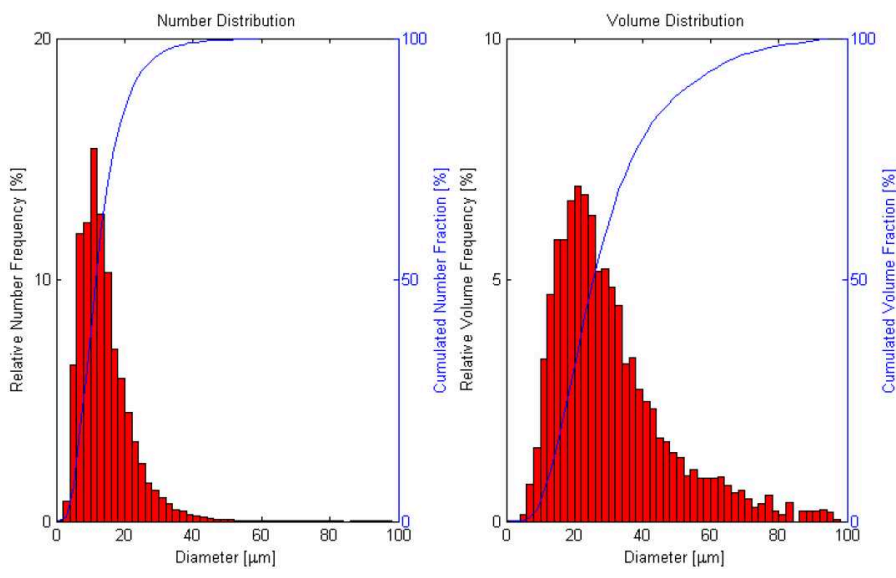

Figure 6. Droplet size distribution and droplet volume distribution of the injector A-A (air-assisted) exhaust gas flow conditions: $300^{\circ} \mathrm{C}, 100 \mathrm{~kg} / \mathrm{h}$.
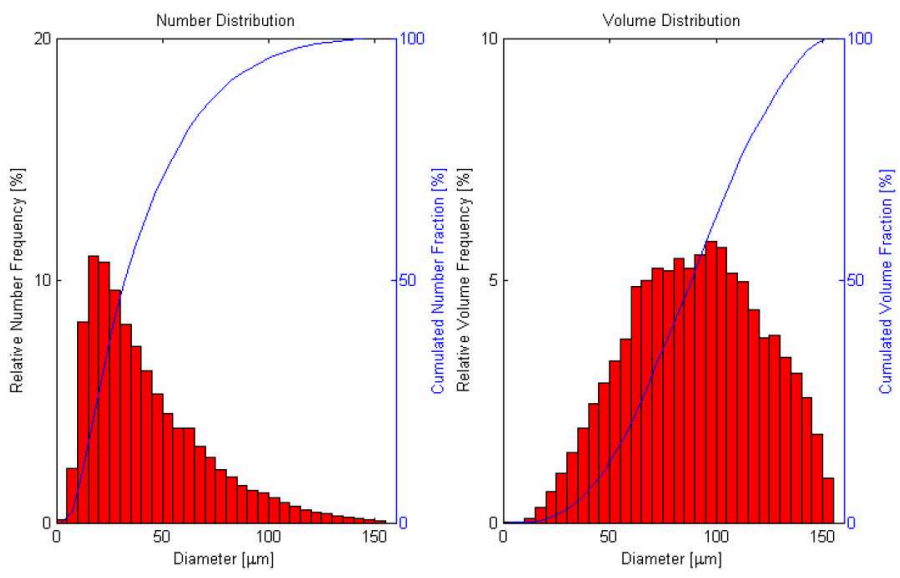

Figure 7. Droplet size distribution and droplet volume distribution of the injector P1-6H (6-Hole pressure-driven) exhaust gas flow conditions: $300^{\circ} \mathrm{C}$, $100 \mathrm{~kg} / \mathrm{h}$.

The air-assisted injector produces much smaller droplets than the pressure-driven injector, and the 6-Hole $\mathrm{P} 2-6 \mathrm{H}$ features with a narrow distribution centralized around $47 \mu \mathrm{m}$. Compare to the three-hole injector $\mathrm{P}-3 \mathrm{H}, \mathrm{P} 2-6 \mathrm{H}$ produces much smaller droplets due to the fact of reduced nozzle diameter, in spite of the same operating pressure and static flow rate. 



Figure 8. Droplet size distribution and droplet volume distribution of the injector P-3H (3-Hole pressure-driven) exhaust gas flow conditions: $300^{\circ} \mathrm{C}$, $100 \mathrm{~kg} / \mathrm{h}$.
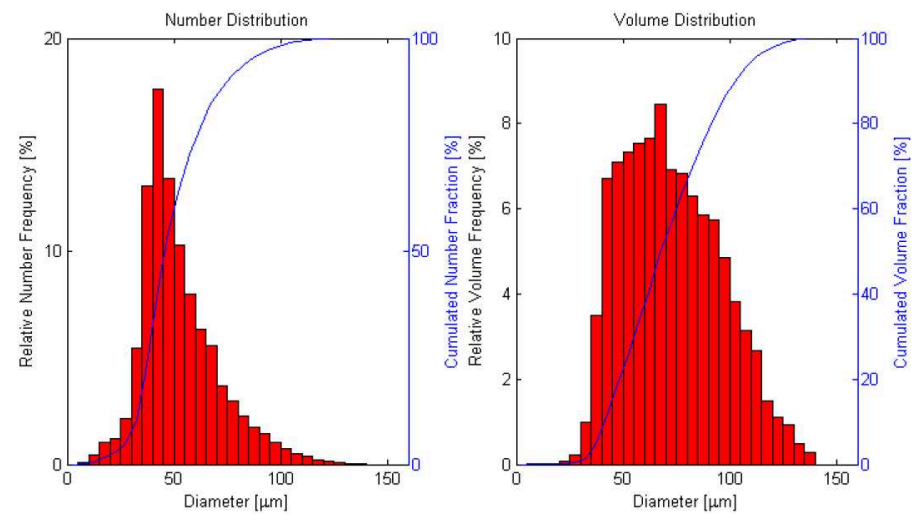

Figure 9. Droplet size distribution and droplet volume distribution of the injector P2-6H (6-Hole pressure-driven) exhaust gas flow conditions: $300^{\circ} \mathrm{C}$, $100 \mathrm{~kg} / \mathrm{h}$.

The most important results from the distributions shown in Figures 6 , $\underline{7}, \underline{8}, \underline{9}$ are summarized in $\underline{\text { Table } 3}$.

Table 3. Summary of droplet size distributions

\begin{tabular}{|c|c|c|c|c|}
\hline & A-A & P1-6H & $\mathrm{P}-3 \mathrm{H}$ & $\mathrm{P} 2-6 \mathrm{H}$ \\
\hline $\begin{array}{l}\underset{\text { maximum }}{\operatorname{mam}]} \text { droplet } \\
\text { size }\end{array}$ & 97 & 153 & 162.5 & 138 \\
\hline $\begin{array}{l}80 \% \text { of droplets } \\
\text { are smaller than } \\
{[\mu \mathrm{m}]}\end{array}$ & 18 & 61 & 80 & 63.5 \\
\hline $\begin{array}{l}80 \% \text { of the droplet } \\
\text { mass is in droplets } \\
\text { smaller than }[\mu \mathrm{m}]\end{array}$ & 41 & 117 & 121.5 & 91.5 \\
\hline $\mathrm{D} 32[\mu \mathrm{m}]$ & 20.4 & 68.7 & 81.4 & 64.5 \\
\hline $\begin{array}{l}80 \% \text { of the spray } \\
\text { mass is in droplets } \\
\text { [min, max] }\end{array}$ & {$[13,55]$} & {$[46,130]$} & {$[13,134]$} & {$[41,103]$} \\
\hline
\end{tabular}

\section{Droplet Velocity Distributions}

Figures $10,11,12,13$ show the mean downward (y-direction in Figure 4) and main flow-directional (x-direction in Figure 4) velocity components together with the error bar at different transverse locations for the four injectors at exhaust flow of $300^{\circ} \mathrm{C}, 300 \mathrm{~kg} / \mathrm{h}$. At this flow condition, the mean gas flow velocity is $21.1 \mathrm{~m} / \mathrm{s}$ and the maximum gas flow velocity $26 \mathrm{~m} / \mathrm{s}$.

The injector axis $(\mathrm{x}=50 \mathrm{~mm})$ can be clearly seen in the velocity profiles of the air-assisted injector, around which there are higher velocity magnitudes in particular of the vertical velocity component. This velocity component decreases towards 0 with increasing distance from the injector axis in the downstream locations. The axial velocities are between 20 and $26 \mathrm{~m} / \mathrm{s}$, close to the mean exhaust gas velocity. Larger droplets have slightly lower velocities which are stabilizing in the downstream locations. This is clear indication that larger droplets are accelerated by the exhaust flow towards the mean flow velocity. Smaller droplets have rather higher axial velocities and slowed down by the flow towards the gas flow velocity.

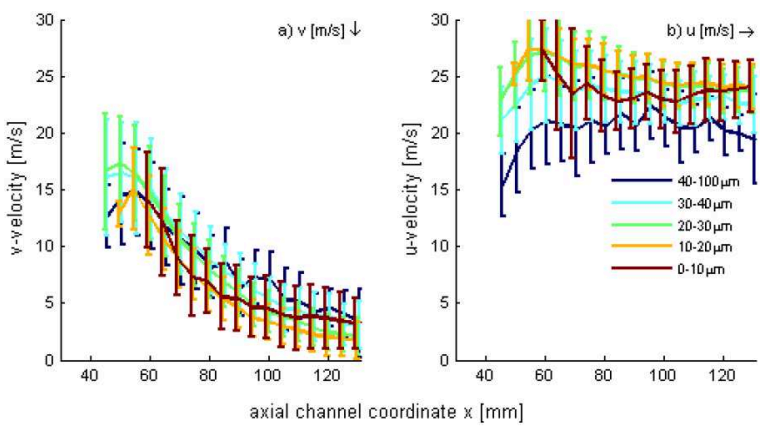

Figure 10. a) Mean downward velocities and b) mean axial velocities for the case of $300^{\circ} \mathrm{C}, 300 \mathrm{~kg} / \mathrm{h}$ at different axial locations for A-A (air-assisted) for different droplet size classes

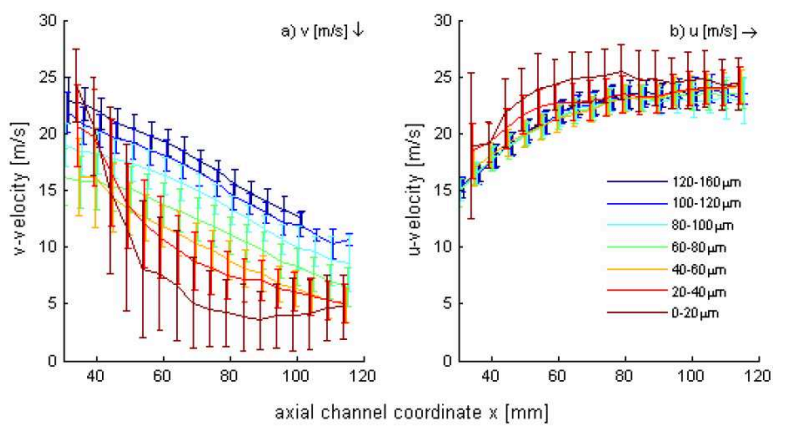

Figure 11. a) Mean downward velocities and b) mean axial velocities for the case of $300^{\circ} \mathrm{C}, 300 \mathrm{~kg} / \mathrm{h}$ at different axial locations for P1-6H (6-Hole pressure-driven) for different droplet size classes.

The velocity components of all the three pressure-driven injectors show different behaviors.

The axial velocity component has very similar characteristics among all three pressure driven injectors (Figures 11, 12, 13). Droplets are accelerated towards the mean exhaust gas velocity in the downstream region and the variance of their velocities is very limited. 
The characteristics of the vertical velocity component distribution differ significantly among the three pressure driven injectors as well as in respect to the air assisted one. All droplets from the $\mathrm{P} 1-6 \mathrm{H}$ injector have similar vertical velocities in the vicinity of the injector axis. Further downstream the bigger droplets have also larger vertical velocity components. Smaller droplets are stronger decelerated. This is due to the aerodynamic drag acting on the droplet, which is inversely proportional to the square of the droplet diameter and proportional to the relative velocity.

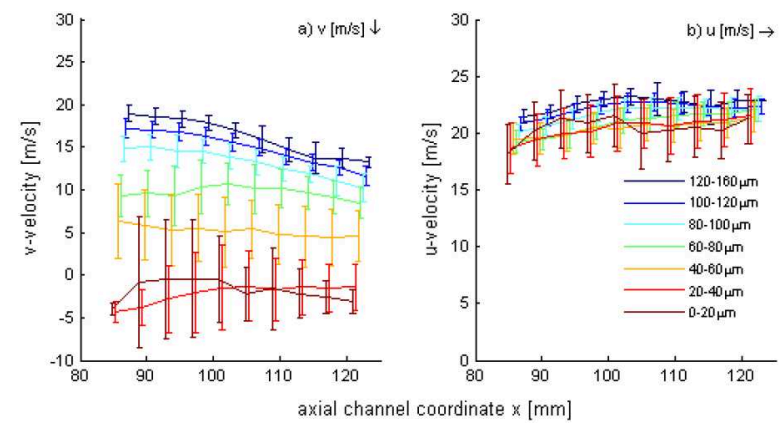

Figure 12. a) Mean downward velocities and b) mean axial velocities for the case of $300^{\circ} \mathrm{C}, 300 \mathrm{~kg} / \mathrm{h}$ at different axial locations for P-3H (3-Hole pressure-driven) for different droplet size classes.

Vertical velocities of droplets from the 3-Hole pressure-driven injector (Figure 12) are less affected by the flow environment: Larger droplets have maintained a large portion of their initial vertical velocities (vertical velocities drop from $20 \mathrm{~m} / \mathrm{s}$ to $14 \mathrm{~m} / \mathrm{s}$. Smaller droplets on the other hand have even negative vertical velocity components. This is clear indication of droplet rebound on the opposed wall.

Droplets form the second tested pressure driven 6-Hole injector, (P2-6H), as seen in Figure 13, have been stronger decelerated in their vertical movement. Bigger droplet velocities are below $13 \mathrm{~m} / \mathrm{s}$ in the downstream locations. Negative downward velocities of smallest droplet size class may imply rebounding effect.

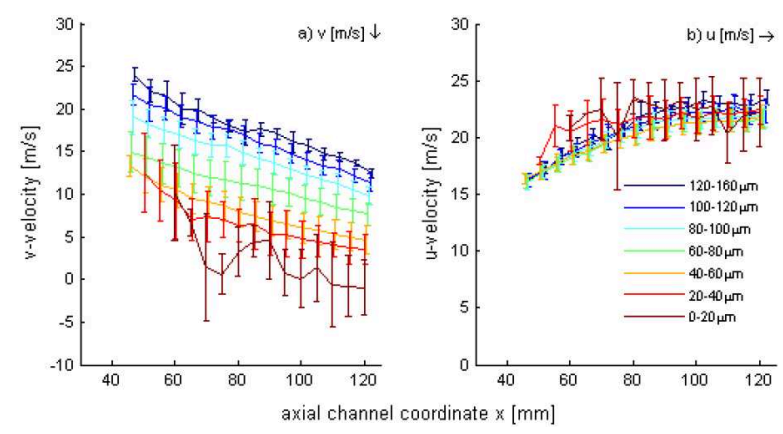

Figure 13. a) Mean downward velocities and b) mean axial velocities for the case of $300^{\circ} \mathrm{C}, 300 \mathrm{~kg} / \mathrm{h}$ at different axial locations for P2-6H (6-Hole pressure-driven) for different droplet size classes.

\section{Droplet Volume Flow Rates}

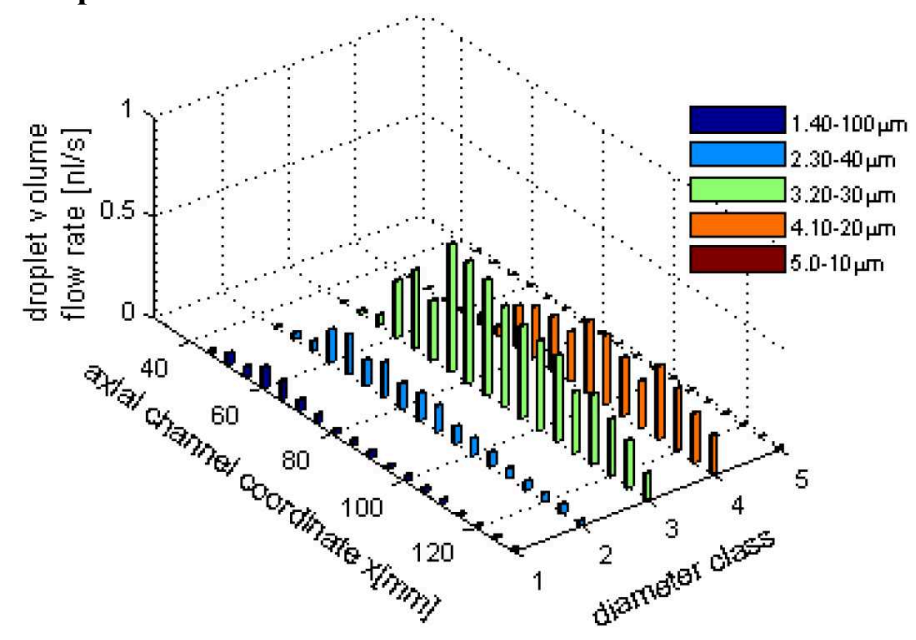

Figure 14. Droplet volume flow rate for the case of $300^{\circ} \mathrm{C}, 300 \mathrm{~kg} / \mathrm{h}$ at different axial locations for the A-A (air-assisted) injector.

The main volume flow of the spray from the air-assisted injector is characterized by droplets between 20 and $40 \mu \mathrm{m}$ in the vicinity of the injector axis $(\mathrm{x}=50 \mathrm{~mm})$. Further downstream the spray volume flow is included in diminishing droplet sizes. While at around $80 \mathrm{~mm}$ downstream the injector exit the spray volume is mainly contained in droplets with diameters in the $20-30 \mu \mathrm{m}$ class, further downstream the prevailing diameter class is $10-20 \mu \mathrm{m}$ (Figure 14).

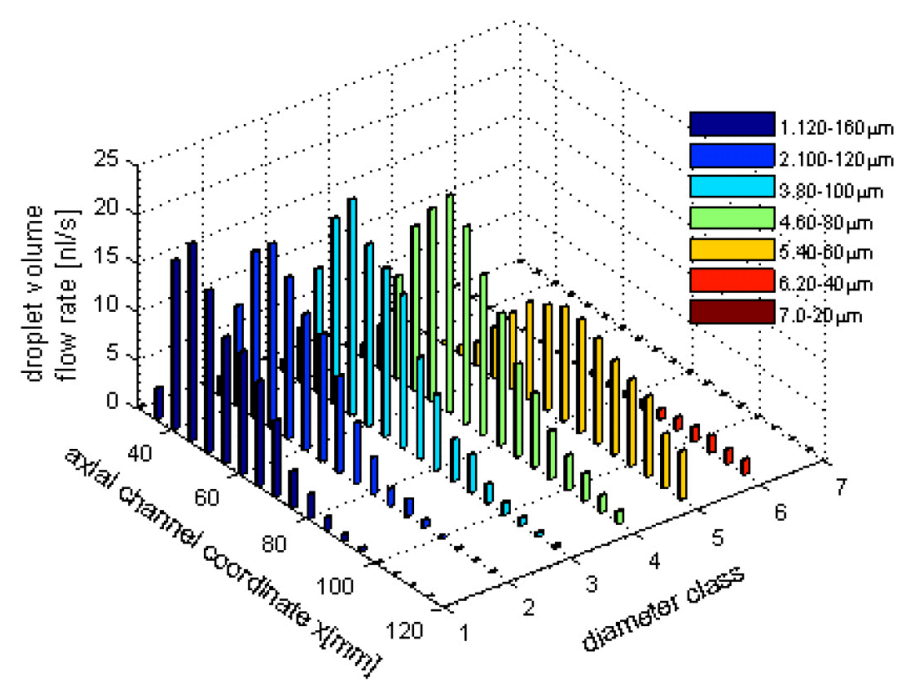

Figure 15. Droplet volume flow rate for the case of $300^{\circ} \mathrm{C}, 300 \mathrm{~kg} / \mathrm{h}$ at different transverse locations for P1-6H (6-Hole pressure-driven) injector.

The main volume part of the spray is distributed in completely different diameter classes if taking into account the 6-Hole injector $\mathrm{P} 1-6 \mathrm{H}$, Figure 15 . In the vicinity of the spray axis $(\mathrm{x}=50 \mathrm{~mm})$ the spray volume is more or less equally distributed in droplets from $80-160 \mu \mathrm{m}$. Further in the downstream (at $\mathrm{x}=100 \mathrm{~mm}$ ) the spray volume is distributed in droplets from 20-60 $\mu \mathrm{m}$. 


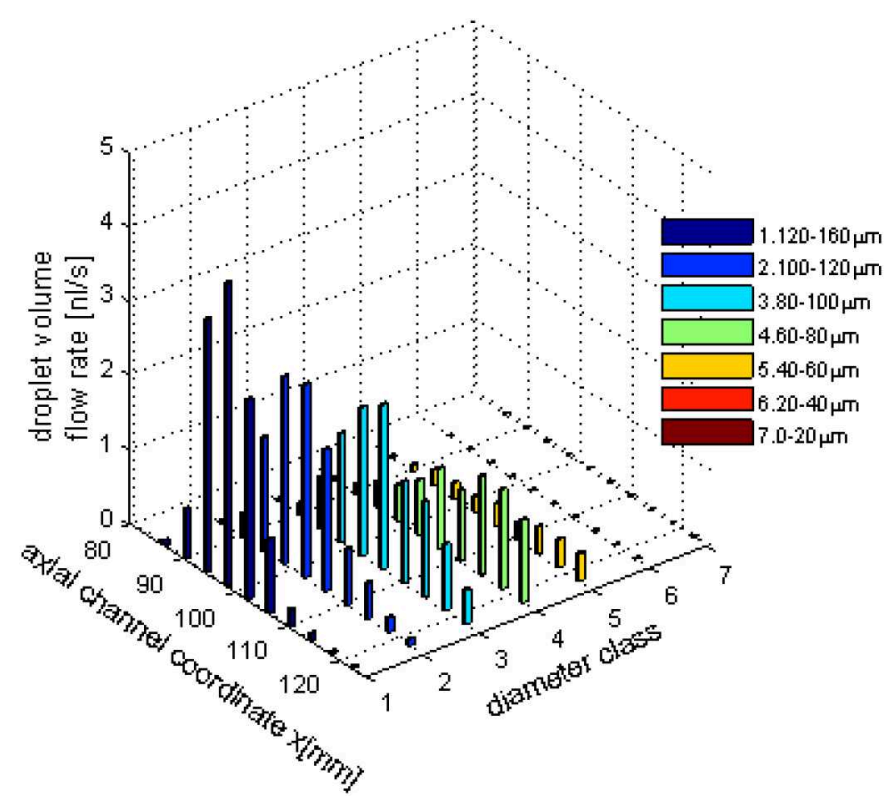

Figure 16. Droplet volume flow rate for the case of $300^{\circ} \mathrm{C}, 300 \mathrm{~kg} / \mathrm{h}$ at different axial locations for P-3H (3-Hole pressure-driven) injector

As already described in the former section, the spray of the 3-Hole injector is consisting of 3 distinct spray cones. Thus the crucial reference point for the characterization is the axis one spray cone and its intersection with the measurement plane at $\mathrm{x}=95 \mathrm{~mm}$. On the axis of this cone the largest part of the spray volume is transported with droplets from $100-160 \mu \mathrm{m}$. Further downstream the droplets carrying significant part of the spray volume are smaller but still larger than $40 \mu \mathrm{m}$.

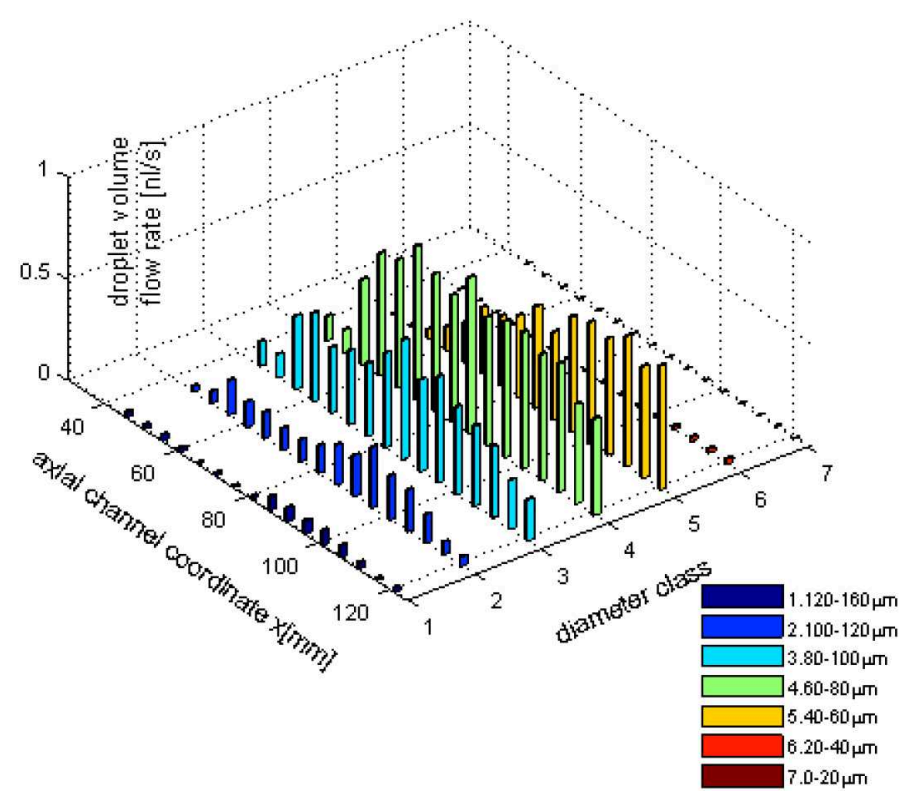

Figure 17. Droplet volume flow rate for the case of $300^{\circ} \mathrm{C}, 300 \mathrm{~kg} / \mathrm{h}$ at different axial locations for P2-6H (6-Hole pressure-driven) injector.
The differences between the two 6-Hole injectors, already discussed in combination with Figures 7 and $\underline{9}$ are also reflected in the spray volume flow rates when comparing Figures 15 and $\underline{17}$. The spray of injector P2-6H contains the largest part of the volume flow in smaller droplets in the vicinity of the injector axis $(60-100 \mu \mathrm{m})$. In respect to the more downstream positions, the majority of the volume flow is in droplets with diameters in the $40-60 \mu \mathrm{m}$ range.

\section{CONCLUSIONS}

SCR spray characteristics differ drastically among available injectors.

- The air-assisted injector generates a spray which is highly susceptible to the exhaust gas flow. Increasing exhaust gas flow deflects strongly the spray and increases entrainment drastically. The result is significantly decreased wetting of the opposed wall.

- $\quad$ The 3-Hole pressure-driven injector generates 3 distinctive spray cones. These cones are only weakly affected by the exhaust flow, propagating on the same direction regardless the exhaust flow intensity. Entrainment though increases with increasing flow rate but only modest.

- The two 6-Hole pressure-driven injectors generate one single spray cone as the six cones merge soon after the nozzles. Only the upwind contour of the spray is affected by the exhaust flow. Entrainment increases with increasing exhaust gas flow in a moderate manner.

- All sprays of the pressure-driven injectors hit the opposed wall at the same location, regardless the exhaust flow conditions.

The droplet size distributions of each injector revealed:

- The air-assisted injector results in smallest droplet sizes.

- The 3-Hole pressure-driven injector is characterized by the largest droplet sizes.

- Injectors P1-6H and P2-6H, the pressure-driven 6-Hole injectors, have similar average droplet sizes. The distribution of the latter is though narrower than of the former. The largest part of the spray mass of the latter is contained in droplets being almost 30\% smaller than of the former.

Mean velocities of droplets in the sprays generated by the injectors tested had significant different characteristics:

- Axial velocities of the droplets generated by pressure-driven injectors in the injector axis were lower than the mean gas velocities. Droplets regardless of size have been accelerated in the downstream towards the mean flow velocities.

- The vertical velocity components of the droplets generated by the pressure-driven injectors had a clear distribution over the droplet sizes:

- Larger droplets are only modestly decelerated by the gases and keep the larger part of their velocity also in the locations far downstream the injector axis. 
Liao et al / SAE Int. J. Engines / Volume 8, Issue 5 (November 2015)

- Smaller droplets are stronger carried by the axial flow and strongly decelerated by the aerodynamic drag in their vertical movement.

- The droplets from the 3-Hole pressure-driven injector reach the opposed wall and rebound.

- Velocities of the droplets from the air-assisted injector behaved similar to the smallest droplets of the pressure-driven injectors. In addition, taking into account entire spray propagation characteristics it can be expected that only a very limited fraction of these droplets will reach the opposed wall with very low velocities. Thus, very limited, if any rebound is expected.

In general the main part of the spray volume flow is contained in larger droplets in the vicinity of the spray or the spray cone axis. Further downstream, the droplet sizes containing the main part of the spray volume are significantly smaller. The air-assisted injector spray is associated with smaller droplets in all investigated locations. Among the pressure-driven injectors significant differences exist in respect to the spray volume distribution over different droplet sizes. The injector location and the vicinity to further parts like the exhaust pipe walls and the catalysts are decisive for the selection of the most suitable injector.

\section{REFERENCES}

1. Johnson, T. Diesel engine emissions and their control: An overview. Platinum Met. Rev. 2008, 52(1), 23-7.

2. Koebel, M.; Elsener, M.; Kleemann, M. Urea-SCR: A promising technique to reduce NOx emissions from automotive diesel engines. Catal. Today 2000, 59, 335-345.

3. Strots, V., Santhanam, S., Adelman, B., Griffin, G. et al., "Deposit Formation in Urea-SCR Systems," SAE Int. J. Fuels Lubr. 2(2):283-289, 2010, doi: $10.4271 / 2009-01-2780$.

4. Xu, L., Watkins, W., Snow, R., Graham, G. et al., "Laboratory and Engine Study of Urea-Related Deposits in Diesel Urea-SCR AfterTreatment Systems," SAE Technical Paper 2007-01-1582, 2007, doi: $10.4271 / 2007-01-1582$.

5. Koebel M.; Strutz E. Thermal and Hydrolytic Decomposition of Urea for Automotive Selective Catalytic Reduction Systems: Thermochemical and Practical Aspects. Ind. Eng. Chem. Res. 2003, 42(10): 2093-2100.

6. Scott Sluder, C., Storey, J., Lewis, S., and Lewis, L., "Low Temperature Urea Decomposition and SCR Performance," SAE Technical Paper 2005-01-1858, 2005, doi:10.4271/2005-01-1858.

7. McKinley, T., Alleyne, A., and Lee, C., "Mixture Non-Uniformity in SCR Systems: Modeling and Uniformity Index Requirements for Steady-State and Transient Operation," SAE Int. J. Fuels Lubr. 3(1):486499, 2010, doi:10.4271/2010-01-0883.

8. Koebel, M.; Elsener, M.; Madia, G. Reaction pathways in the selective catalytic reduction process with $\mathrm{NO}$ and $\mathrm{NO} 2$ at low temperatures. Ind. Eng. Chem. Res. 2001, 40(1), 52-59.

9. Koebel, M.; Madia, G.; Elsener, M. Selective catalytic reduction of NO and NO2 at low temperatures. Catal. Today 2002, 73(3-4), 239-247.

10. Girard, J., Snow, R., Cavataio, G., and Lambert, C., "The Influence of Ammonia to NOX Ratio on SCR Performance," SAE Technical Paper 2007-01-1581, 2007, doi:10.4271/2007-01-1581.

11. Madia, G.; Koebel, M.; Elsener, M.; Wokaun, A. The effect of an oxidation precatalyst on the NOx reduction by ammonia SCR. Ind. Eng. Chem. Res. 2002, 41(15), 3512-3517.

12. Kleemann, M.; Elsener, M.; Koebel, M.; Wokaun, A. Hydrolysis of isocyanic acid on SCR catalysts. Ind. Eng. Chem. Res. 2000, 39(11), 4120-4126.

13. Schaber, P. M.; Colson, J.; Higgins, S.; Thielen, D.; Anspach, B.; Brauer, $\mathrm{J}$. Thermal decomposition (pyrolysis) of urea in an open reaction vessel. Thermochim. Acta 2004, 424(1-2), 131-142.
14. Yim, S. D.; Kim, S. J.; Baik, J. H.; Nam, I.-S.; Mok, Y. S.; Lee, J.-H.; Cho, B. K.; Oh, S. H. Decomposition of urea into NH3 for the SCR process. Ind. Eng. Chem. Res. 2004, 43(16), 4856-4863.

15. Steinbach, S., Grünwald, J., and Sattelmayer, T., "Urea-SCR-Technology - Performance of Structured Metallic Substrates," SAE Technical Paper 2006-01-3505, 2006, doi:10.4271/2006-01-3505.

16. Rajadurai, S., "Improved NOx Reduction Using Wiremesh Thermolysis Mixer in Urea SCR System," SAE Technical Paper 2008-01-2636, 2008, doi: $\underline{10.4271 / 2008-01-2636}$.

17. Gehrlein J.; Lang A.; Palmer G. Optimierung von SCR-Systemen durch Integration von Mischelementen, Motortech. Z. 2009, 70, 218-223.

18. Way, P., Viswanathan, K., Preethi, P., Gilb, A. et al., "SCR Performance Optimization Through Advancements in Aftertreatment Packaging," SAE Technical Paper 2009-01-0633, 2009, doi:10.4271/2009-01-0633.

19. Jeong S. J.; Lee S. J.; Kim W. S. Numerical Study on the Optimum Injection of Urea-Water Solution for SCR DeNOx System of a HeavyDuty Diesel Engine to Improve DeNOx Performance and Reduce NH3 Slip. Environ. Eng. Sci. 2008, 25(7): 1017-1036.

20. Jeong, S., Lee, S., Kim, W., and Lee, C., "Simulation on the Optimum Shape and Location of Urea Injector for Urea-SCR System of Heavyduty Diesel Engine to Prevent NH3 Slip," SAE Technical Paper $2005-$ 01-3886, 2005, doi:10.4271/2005-01-3886.

21. Chen, M. and Williams, S., "Modelling and Optimization of SCRExhaust Aftertreatment Systems," SAE Technical Paper 2005-01-0969, 2005, doi: 10.4271/2005-01-0969.

22. Birkhold F.; Meingast U.; Wassermann P.; Deutschmann O. Modeling and simulation of the injection of urea-water-solution for automotive SCR DeNOx-systems. Appl. Catal., B 2007, 70(1):119-127.

23. Birkhold, F., Meingast, U., Wassermann, P., and Deutschmann, O., "Analysis of the Injection of Urea-Water-Solution for Automotive SCR DeNOx-Systems: Modeling of Two-Phase Flow and Spray/ Wall-Interaction," SAE Technical Paper 2006-01-0643, 2006, doi: $10.4271 / 2006-01-0643$.

24. Montenegro G.; Onorati A. 1D thermo-fluid dynamic modelling of deNOx SCR systems for diesel engine exhaust gas after-treatment. Int. J. Veh. Des. 2006, 41(1-4), 285-306.

25. Sharifian, L., Wright, Y., Boulouchos, K., Elsener, M. et al., "Transient simulation of NOx reduction over a Fe-Zeolite catalyst in an NH3-SCR system and study of the performance under different operating conditions," SAE Int. J. Fuels Lubr. 5(1):370-379, 2012, doi: $10.4271 / 2011-01-2084$.

26. Sharifian L.; Wright Y. M.; Boulouchos K.; Krö, cher O. Calibration of a model for selective catalytic reduction with ammonia, including NO oxidation, and simulation of NOx reduction over an Fe-zeolite catalyst under highly transient conditions. Int. J. Engine Res. 2013, 14(2):107121.

27. van Helden, R., Verbeek, R., Willems, F., and van der Welle, R., "Optimization of Urea SCR deNOx Systems for HD Diesel Engines," SAE Technical Paper 2004-01-0154, 2004, doi:10.4271/2004-01-0154

28. Spiteri, A.C.; Dimopoulos Eggenschwiler P. Experimental Fluid Dynamic Investigation of Urea-Water Sprays for Diesel SCR-DeNOx Applications. Industrial \& Engineering Chemistry Research, 2014. 53: p. 3047-3055.

29. Varna, A., Boulouchos, K., Spiteri, A., Dimopoulos Eggenschwiler, P. et al., "Numerical Modelling and Experimental Characterization of a Pressure-Assisted Multi-Stream Injector for SCR Exhaust Gas After-Treatment," SAE Int. J. Engines 7(4):2012-2021, 2014, doi:10.4271/2014-01-2822.

30. Varna A.; Spiteri A. C.; Wright Y. M.; Dimopoulos Eggenschwiler P.; Boulouchos K. Experimental and numerical assessment of impingement and mixing of urea-water sprays for nitric oxide reduction in Diesel exhaust. Appl. Energy (2015). doi:10.1016/j.apenergy.2015.03.015.

31. Spiteri A.C.; Dimopoulos Eggenschwiler P.; Liao Y.; Wigley G.; Michalow-Mauke K. A.; Elsener M.; Kröcher O.; Boulouchos K. Comparative analysis on the performance of pressure and air-assisted urea injection for SelectiveCatalytic Reduction of NOx, Fuel, under review, 2015.

32. Liao Y.; Nocivelli L.; Dimopoulos Eggenschwiler P.; Spiteri A. Experimental investigation of urea-water sprays in Selective Catalytic Reduction (SCR) systems Proceedings of the 15th Stuttgart International Symposium, Automotive and Engine Technology, vol. 2,155-169, 2015. 


\section{ACKNOWLEDGEMENTS}

The authors gratefully thank and wish to acknowledge the support of the following institutions and partners:

Environmental Technology Promotion of the Swiss Federal Office for the Environment (FOEN) - BAFU project DeMiCo.

Liebherr Machines Bulle S.A., Bulle, Switzerland.

Swiss Oil Association (Forschungsfonds der Erdoel-Vereinigung),

Zürich, Switzerland.

CNH Industrial, FPT Motorenforschung AG, Arbon, Switzerland.

\section{CONTACT INFORMATION}

Yujun Liao

EMPA Dübendorf

Überlandstrasse 129

CH-8600 Dübendorf

Switzerland

Yujun.Liao@empa.ch

www.empa.ch

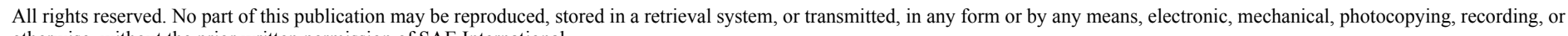
otherwise, without the prior written permission of SAE International.

Positions and opinions advanced in this paper are those of the author(s) and not necessarily those of SAE International. The author is solely responsible for the content of the paper. 